\title{
Climate Change Ethics: Navigating the Perfect Moral Storm, by Donald A. Brown. London and New York: Earthscann from Routledge, 2013'
}

\author{
Małgorzata Dereniowska (Greqam, AMSE, Aix-Marseille University)
}

Climate change poses one of the most serious challenges for humanity due to the increasing complexity of both factual and ethical dimensions. Although the debate over climate change is usually framed as a debate about scientific facts, climate change is also fundamentally an ethical issue; the challenges that climate change poses cannot be addressed simply by accumulating more factual knowledge since it also refers to the meaning we make out of the world and the values we identify as important. Among climate ethicists, there are no doubts that even in the face of uncertainty regarding the severity, scope, and form of climate change impacts, the moral problems it poses are real. For example, future generations are subjected to severe harms and risk, and there exists a great deal of conflict in international climate negotiations. There is general agreement that actions undertaken to deal with the problem of global climate change are not sufficient. Addressing climate issues is usually conceived in terms of political decision making, with adaptation and mitigation as the primary goals. The fact of scientific uncertainty regarding the severity and scope of the problem fuels general disagreement about the appropriate actions to undertake. As a result, the persistent tendency to polarize the discourse often undermines the moral importance of human action, especially that which relates to the global commons and future generations.

A notable element of climate change is the fact that both benefits and harms are immensely disaggregated: the climate change problem is caused by people concentrated in one part of the globe who benefit from actions that induce environmental harms (mostly in economic terms), whereas the people most vulnerable to the effects of climate change are isolated both spatially (mostly in the South) and temporally (future generations). This feature of climate change makes it susceptible to the problem of moral corruption by institutions and the people facing it - expressed by Stephen Gardiner in the metaphor of a perfect moral storm. In the midst of this difficulty, and in light of

1 This work has been carried out thanks to the support of the A*MIDEX project (no ANR-11-IDEX-0001-02) funded by the "Investissements d'Avenir" French Government program, managed by the French National Research Agency (ANR). 
the overwhelming inertia of climate change policy in general, there is a need not so much for new concepts, but for competences and skills that can enable us to cope with transformation. What is needed is increased capacity to navigate the moral storm of climate change. Such competences, combined with scientific literacy, are necessary to appropriately situate and perform the moral reasoning required in public discourse. Thus, bridging the gap between new scientific findings and an adequate policy response needs to be supplemented and supported by ethical reasoning.

Consequently, one of the lessons from the growing field of climate ethics is the necessity of bridging the gap between the scientific, political, and moral realms, especially when thinking about climate policy. There is an urgent need to base political discussions on social and ethical argumentation and reasoning. Donald A. Brown's book, Climate Change Ethics: Navigating the Perfect Moral Storm, aims at filling this gap. Climatic changes and disruptions require human intervention on the global level, and "there is little hope of achieving a just solution to climate change unless moral arguments are made" (4). Brown also emphasizes the indispensability of persuasive moral arguments in pushing needed social change in prosperous social movements (5). A relevant climate ethics cannot be abstracted from the pressing reality of environmental problems and social inequalities. Brown's underlying argument resembles Amartya Sen's motivation to develop a pragmatic, comparative approach to justice instead of searching for the ideal; the criticism being that focusing primarily on ideal requirements of justice by ethicists is a practical mistake (10). The urgency of climate change raises the practical requirement for action, which both demands ethical scrutiny in public and political discourse on climate policies and mitigation and adaptation goals, and requires ethicists to adopt a more pragmatic, practical approach to the moral analysis of pressing global problems. Brown searches to deliver an "overlapping consensus" regarding ethical conclusions for climate change policy that would be supported by most, if not all, major ethical theories. Importantly, even if the result of ethical issue-spotting is disagreement regarding what ethics requires, an equally important outcome is agreement as to what is ethically condemnable (14).

The argument of the book is outlined in three parts. The first is a historical overview of the scientific and public debate about climate change. The second articulates and justifies the most important ethical issues in the climate change policy debate. The third part, by emphasizing the crucial role of ethics in policy making on climate matters, deals with the reasons for the failure of ethics to seriously impact climate change policy, and offers guidance as to how we can navigate the perfect moral storm. The structure of the arguments is built on the careful synthesis and critical analysis of climate science and economics, combined with a rigorous ethical issue-spotting of relevant problems arising at the science/policy interface. Each part concludes 
with practical guidance as to how to navigate the perfect moral storm of climate change. This includes lists of ethical issues, related duties (founded firmly on the overlapping consensus of mainstream moral theories), and recommendations.

There are two main points in Brown's diagnosis. First, climate change "triggers duties, obligations, and responsibilities of high-emitting countries and individuals to the poor victims of climate change around the world" (13). Second, opposing climate policies on the basis of costs, uncertainty arguments, and national interest is a morally untenable position. To illustrate this point, moral conflict arises between using cost-benefit analysis as a policy guide and the ethical obligation to prevent harm caused by climate change that is owed to all people (61). First, the economic opportunity costs (the costs of choosing one option over another that is equally desirable) that are assigned to the policy alternative that generates greater benefits does not work in the situation where costs and benefits are disaggregated in time and space. Second, the problem of the disaggregation of benefits and burdens challenges reliance on cost-benefit analysis (CBA) as the guide for climate policy since the costs fall on different people from those benefiting from the policies of climate change adaptation and mitigation (60). One of the main ethical problems with the use of CBA in this context is that it is often used to look at the harms and benefits only within one country. Brown forcefully makes the case for how the (mis)use of CBA by the Clinton administration led to the legitimization of ignoring negative consequences beyond the borders of the U.S.

These conclusions, if taken with due respect and paired with societal action, would in consequence change the tapestry of climate change negotiations and policy making. The problem of the moral austerity in climate change decision making and policy formation is twofold. First, "there has been a 35 years debate about what should be done to reduce climate change's immense threat [...] that has utterly failed to recognize the ethical dimensions of human-induced global warming" (3). Second, ethical analysis needs to be made more relevant to actual moral issues in searching for solutions to climate change. Thus, the challenge of navigating the perfect moral storm is to make sure that ethical reflection is an important consideration in the climate change debate, and that ethical analysis is sensitive to issues inherent in policy making. The strategy of integrating ethics with policy-making is not without difficulties, however. Brown points out that one of the most serious challenges lies with connecting ethical arguments with social action: "Ethicists educating people about the ethical dimensions of climate change are not likely to make much significant difference in the failure of national governments and other entities to take their responsibilities seriously. The world needs widespread and rapid social change, particularly in high-emitting countries, which establishes widely held norms" (249). Such a systemic change is possible, in other words, only when social action is able to communicate the position that 
climate change, as a moral problem, must be resolved collectively based on the acceptance of global responsibilities.

Brown develops an account of climate ethics aimed at navigating the moral storm of climate change consisting of the following parts. He combines concerns of distributive justice with a global ethics framework that is pluralistic (where necessarily various considerations are taken into account: consequentialist, rights-based, and justice-based approaches), and ethical issue-spotting in climate change discourse in the public sphere. Important features of climate ethics are its cosmopolitan character ("People have duties to other people regardless of where they are situated" (62) and a commitment to global citizenship. Brown's approach is practical in the sense that although he clearly acknowledges and thoroughly discusses the challenges that climate change poses to moral categories, theories, and thinking, he also points out that in order to have an ethically legitimate framework it is not necessary to build a new climate ethic from scratch. Mainstream ethical theories provide enough grounds for conducting ethical analysis and deriving the needed principles and duties: "All mainstream ethical theories assume that people have responsibilities to all human beings regardless of where they are located to do no harm" (63). The principle of non-harm, which is justified in diverse moral traditions, can be thus considered to be the basic universal standard of climate ethics. Brown further discusses various proposals for the stabilization of greenhouse gases at levels thought to be safe, and an allocation framework of greenhouse gas emissions between nations in light of principles of substantive, procedural, and distributive justice. These must, according to Brown, pass the test of ethical scrutiny and take equity into account: "atmospheric greenhouse concentration levels will determine who dies, whose ecological systems on which life depends will survive, and even which nations endure" (147); every nation has a duty to keep its national emission levels below its fair share of global emissions.

The strength of Brown's argument consists of the following components: a deep knowledge and rigorous synthesis of climate science (both historical and current); a careful ethical issue-spotting and moral analysis that employs the main moral theories (deontology and consequentialism) in evaluating the relevant ethical questions, problems, and dilemmas; and finally, a down-to-earth and sophisticated ethical analysis in the form of practical guidance. The combination of these components makes his contribution to navigating the moral storm of climate change unique. From the methodological point of view, the book involves not only a blending of multidisciplinary perspectives on climate change (from climate sciences, political theory, and moral philosophy), but also interdisciplinary practice in thinking across disciplinary boundaries and proficiently maneuvering between the contested facts and moral analysis. 
One of the things Brown's book does not do, however, is provide much ethical guidance for the individual reader in terms of what he or she might do to navigate the moral storm of climate change since it is cast at the level of larger social inequalities. Brown's discussion of individual duties and obligations are offered, for example, in the context of the conventional framing that juxtaposes the North and the South, with the South being justified in keeping to their current emissions levels due to historical inequalities and rights to development. Brown points out that in contrast to the usual NorthSouth framing of the climate conflict by the international community, the real dichotomy is between the rich and the poor in both hemispheres. From within this context, there are different levels of discussion about duties and obligations: the international (where the distinction between luxury emissions versus survival emissions of the poor applies) (199), and the smaller levels of organization, from sub-national governments to organizations, businesses, and finally individuals.

Yet, there is room for further exploration of the ethical issues involved in the individual consumption of energy and emissions. For example, the themes that may arise upon reflection from the point of view of individualistic ethics touch upon the question of the grounding of a sense of responsibility in individuals that stretches the classical and historically categories of moral agency and moral duty. Another issue is how to combine the requirement of setting the emission targets on the basis of "equal per capita emissions level necessary to prevent dangerous climate change or other relevant morally acceptable considerations that would justify moving away from global per capita allocations" (210) with individual and group participation and empowerment. On the one hand, this distributive approach to individual duties hinders the difference between individual capabilities, diverse goals, and life situations. On the other hand, an individual who accepts her moral duty to address climate change in her actions, and searches for guidance and recommendations for maneuvering through the ambiguity of its moral analysis, might be left with few details. This gap, however, offers an excellent opportunity for further work on the individual dimension of navigating the moral storm of climate change.

To conclude, Brown's book is a masterpiece of ethical analysis adjusted to the moral challenges of climate change. As he points out, "There is not just one central issue raised by climate change, but different civilisationchallenging ethical issues that raise diverse ethical questions which should be considered in global warming policy formation" (7). Brown succeeds not only in distinguishing the multifaceted issues and asking the relevant ethical questions (with regard to national and other relevant levels), but also in providing carefully reasoned conclusions and a detailed prescriptive guide for practitioners involved in the climate change debate, negotiations, and decision making. Consequently, Brown succeeds in delivering what he calls for at the 
beginning of his book: practically relevant prospective ethical analysis accessible to practitioners that can serve as a basis for developing responsible and morally legitimate climate policy.

Donald Brown offers a practical ethical guide to analyzing questions of climate change policy making, which also happens to represent a growing trend in moral philosophy that focuses not so much on abstract theoretical questions, but on the real world. His book should be of interest to students, scholars, practitioners, and anybody else genuinely interested in making progress on climate change policy.

Ethics in Progress (ISSN 2084-9257). Vol. 5 (2014). No. 1. pp. 151-156.

doi:10.14746/eip.2014.1.8 